\title{
Interaction rates of group-III and group-V impurities with intrinsic point defects in irradiated Si and Ge*
}

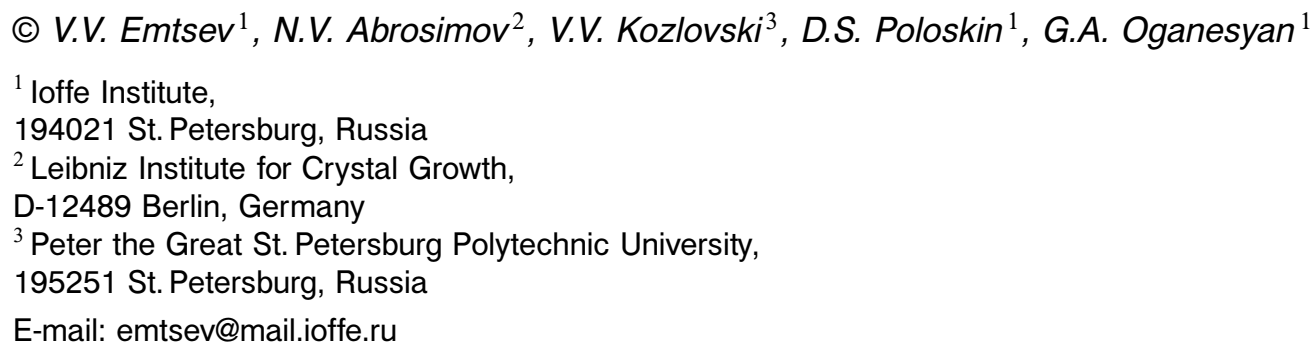

(Received 26.04.2018. Received offer revision 20.08.2018)

A comparative study of interactions of shallow impurities with primary defects in oxygen- and carbon-lean moderately doped $\mathrm{Si}$ and $\mathrm{Ge}$ subjected to irradiation with $0.9 \mathrm{MeV}$ electrons, ${ }^{60} \mathrm{Co}$ gamma-rays, and $15 \mathrm{MeV}$ protons at room temperature is presented and discussed. For the quantitative characterization of such interactions, changes in the total concentration of the original shallow group-V donor or group-III acceptor impurities in the irradiated materials are determined by Hall effect measurements over a wide temperature range. Losses of the shallow donor or acceptor states in the irradiated $\mathrm{Si}$ and $\mathrm{Ge}$ are indicative of their removal rates that can be used for estimation of production rates of primary defects interacting with the dopants. Some important factors affecting the interactions between primary defects and shallow impurities in $\mathrm{Si}$ and Ge are highlighted.

DOI: $10.21883 /$ FTP.2018.13.46869.8970

* Полный текст статьи опубликован в переводной версии журнала „Физика и техника полупроводнивков“ - SEMICONDUCTORS (T. 52. Вып. 13). 